\title{
A proposição de um plano de ensino e aprendizagem de violino em grupo no curso superior na perspectiva de estudantes, professores e avaliadores externos
}

\section{Fredi Gerling Regina Antunes Teixeira dos Santos}

Resumo: O presente artigo discute a perspectiva de avaliação da aprendizagem de alunos de violino recém-ingressos $(\mathrm{N}=6)$ em curso superior de música sob a óptica dos estudantes, bem como de avaliadores externos. As técnicas de coletas de dados na investigação foram: (i) registros em áudio e vídeo; (ii) auto-avalição e (iii) Descrição de pontos fortes e fracos nos produtos. Para os árbitros, os pontos fortes foram referentes à técnica da mão direta (ponto de contato; divisão, uso e planejamento do arco) e demostraram menor progresso em termos de: mão direita (excesso de energia do uso do arco, tensão no braço direito, pressão e velocidade do arco). Os estudantes em suas auto-avaliações focaram-se no domínio e coordenação do arco.

Abstract: This paper discusses the evaluation of learning in college violin students $(\mathrm{N}=6)$ at the freshman level. It deals with the self-evaluations of the students as well as those of independent judges. Data was collected (i) through audio-video recordings; (ii) Students self-evaluations; (iii) Independent judges $(\mathrm{N}=6)$ evaluations of strengths and weaknesses observed on the recordings. These judges singled out as positive improvements of bow technique aspects such as contact point, bow distribution as well as phrasing and tone production including vibrato. Aspects such as excessive pressure or inadequate speed of bow, tension and high elbow were considered less improved along with issues of rhythmic control due to phrase shortenings and unevenness. The students' selfevaluations focused mainly on bow control and coordination 
Mas digo sinceramente, na vida, a coisa mais feia / É gente que vive chorando de barriga cheia (Zeca Pagodinho).

Nos últimos anos o governo brasileiro, através da expansão de seu sistema de universidades, tem procurado possibilitar que um número maior de jovens tenha acesso à educação superior (Brasil, 2014). Nos últimos anos presenciamos a criação de vários departamentos de música em novas universidades e também em universidades já estabelecidas que buscam atender a demanda das suas comunidades. Paralelamente, vemos um grande número de projetos sociais baseados em música, por todo o pais.

Esta situação que a longo prazo é sem duvida positiva, no momento presente vem criando uma situação de conflito entre a demanda por preenchimento das vagas criadas e a inexistência de alunos qualificados para seguir o curso superior de Música. Em algumas instituições de ensino foi eliminado o teste de habilitação específica para Música e em outras há recomendações para "flexibilização" nos critérios de avaliação.

A nossa epigrafe é uma lembrança de que nunca tantos recursos públicos foram investidos no sistema universitário federal. Acredito que ao invés de protestar contra uma situação que será benéfica ao pais no decorrer dos anos, devemos buscar novas alternativas que poderão contribuir para que os benefícios destes investimentos de recursos públicos aconteçam mais rapidamente. Este artigo relata uma pesquisa que buscou subsídios para embasar uma proposta de alternativas positivas para esta situação. 


\section{O Problema}

No final de 2010 recebemos um email com o seguinte texto:

Prezados colegas, ontem tivemos uma reunião plenária na qual foram apresentadas e discutidas questões importantes sobre a Prova Específica. (...) Entre outros assuntos, foi resolvido que haverá uma flexibilização nos critérios de avaliação e no nível de exigência, visando uma maior aprovação de candidatos;

Em decorrência desta flexibilização de critérios, o setor de cordas da UFRGS aceitou um número de alunos que demonstravam potencial, mas que não tinham uma formação técnica a altura das exigências do curso de bacharelado em instrumentos.

\section{A proposição de um plano de ensino e aprendizagem em grupo}

Devemos ter sempre em mente que o custo de cada hora aula na Universidade Brasileira é pago pelo contribuinte. Portanto, devemos otimizar os recursos públicos. Após a realização da prova específica, no final de 2010, minha colega Hella Frank e eu nos reunimos para avaliar a nossa carga horária do semestre seguinte. Ao analisarmos o estágio de conhecimento de cada aluno que iria ingressar em 2011 constatamos que teríamos que apresentar conteúdos básicos para todos. No sistema de uma aula semanal para cada aluno não teríamos tempo para apresentar todos os conteúdos que julgávamos necessários. Assim sendo, decidimos que as aulas seriam dadas em grupo. Como tínhamos um total de nove alunos, teríamos nove horas aulas atribuídas aos professores, mas os alunos só teriam uma hora aula semanal. Portanto, programamos duas aulas coletivas por semana com dois professores trabalhando conteúdos programados de acordo com as necessidades 
dos alunos. Nesta proposta, cada aluno recebeu quatro horas aula semanais ao invés de uma, enquanto os professores tiveram disponibilidade para atender as necessidades de toda a classe. As aulas coletivas foram divididas para introduzir aspectos básicos musicais e técnicos. A professora Hella Frank trabalhou os aspectos musicais aplicados ao instrumento enquanto este autor trabalhou a técnica básica do instrumento.

No estabelecimento do plano de ação inicial foi necessário detalhar aspectos que permitissem aos alunos adquirir vocabulário e conceitos básicos da técnica do violino, e a partir dessa sistematização poder atuar de forma reflexiva e direcionada sobre os desafios a serem enfrentados nos seus estudos diários, além de poderem registrar suas conquistas atingidas. Para Kraus e Chandrasekaran (2010), o treinamento musical induz uma melhoria no processamento dos sinais auditivos, que por sua vez depende da natureza desse treinamento, bem como das estratégias de prática envolvidas. Assim, os aspectos técnicos básicos introduzidos nas aulas serviram como plano de aula e revisões para os alunos em termos de exercícios de relaxamento, postura, técnica básica de mão esquerda e mão direita, associados a exercícios direcionados ao treinamento auditivo, ou seja, exercícios de sensibilização dos estudantes a ouvir e focar-se atentamente na qualidade dos parâmetros sonoros.

Os aspectos técnicos e musicais básicos também seriam trabalhados tanto no contexto do repertório a ser preparado pelos alunos, como também em uma peça comum a todos os estudantes ingressantes. Portanto, a peça de J.S. Bach que todos executaram na prova do vestibular foi considerada um controle para auferir se os alunos conseguiriam aplicar de maneira autônoma os conteúdos introduzidos ao longo do semestre.

O contexto de ensino e aprendizagem que iriamos vivenciar ao longo de um semestre acadêmico evidenciou-se como potencial para a reflexão dos produtos ai atingidos. Assim foram convidados avaliadores 
externos ao programa para aferir sobre o potencial desenvolvimento dos alunos frente a essa proposta de ensino pré-elaborada. Concomitantemente, os alunos foram convidados a participar da investigação tanto como estudantes-participantes como avaliadores de seus próprios produtos. Tal procedimento visou envolvê-los no processo de aprendizado e no desenvolvimento da autonomia.

$\mathrm{Na}$ proposta, não oferecemos comentários ou sugestões específicos para a execução da obra de referência. Nosso objetivo foi avaliar se os alunos seriam capazes de aplicar os conhecimentos obtidos nas aulas coletivas e mostrar progresso na sua execução da peça de cotejo. As informações abaixo foram as únicas informações dadas a todos os participantes no que tange a peça de J.S. Bach.

Figura 1 - Instruções para estudo da peça comum a todos os estudantes do semestre.

Programe-a no seu plano de estudos regularmente

Pense no que você quer fazer e como você quer que a música soe.

Utilize no seu estudo desta peça, os conteúdos que estão sendo estudados nas aulas coletivas do Prof. Fredi e da Profa. Hella

Use estes conhecimentos para reforçar suas idéias ou para ref ormulálas.

A próxima gravaçăo que será dia 28 de abril de 2011 será disponibilizada para você proggramar seu estudo para a gravação final do dia 9 de jumho de 2011.

Assim, o objetivo do presente artigo é discutir a perspectiva de avaliação da aprendizagem de alunos de violino recém-ingressos em curso superior de música, a partir de uma proposição de ensino de 
violino coletivo, sob a óptica dos estudantes participantes, bem como de avaliadores externos.

\section{O delineamento}

A presente investigação ocorreu ao longo de um semestre acadêmico e contou com a participação inicial de 9 estudantes de cordas ( 1 de viola e 8 de Violino), assim como 6 avaliadores externos, professores pertencentes a universidades brasileiras. Dos 9 estudantes convidados, seis concluíram todas as etapas da investigação. A média de idade desses participantes foi de 19 anos. A Figura 2 ilustra o cronograma do delineamento proposto em termos de plano de ensino e das etapas de avaliação.

A técnica de coletas de dados na investigação foi a observação de produtos (inicial e final) dos estudantes registrados em áudio e vídeo durante o semestre acadêmico. Para este fim, solicitamos que os alunos estivessem preparados para executar esta peça desde o primeiro dia de aula. Na ocasião do registro, após a apresentação do projeto de pesquisa e, obtido o consentimento dos alunos, realizamos a primeira gravação em vídeo que serviu de referencia para a avaliação posterior tanto dos próprios alunos como dos avaliadores externos. 
Figura 2 - Cronograma de atividades de ensino coletivo de violino, coleta dos produtos dos estudantes investigados e avaliação por árbitros externos e estudantes.

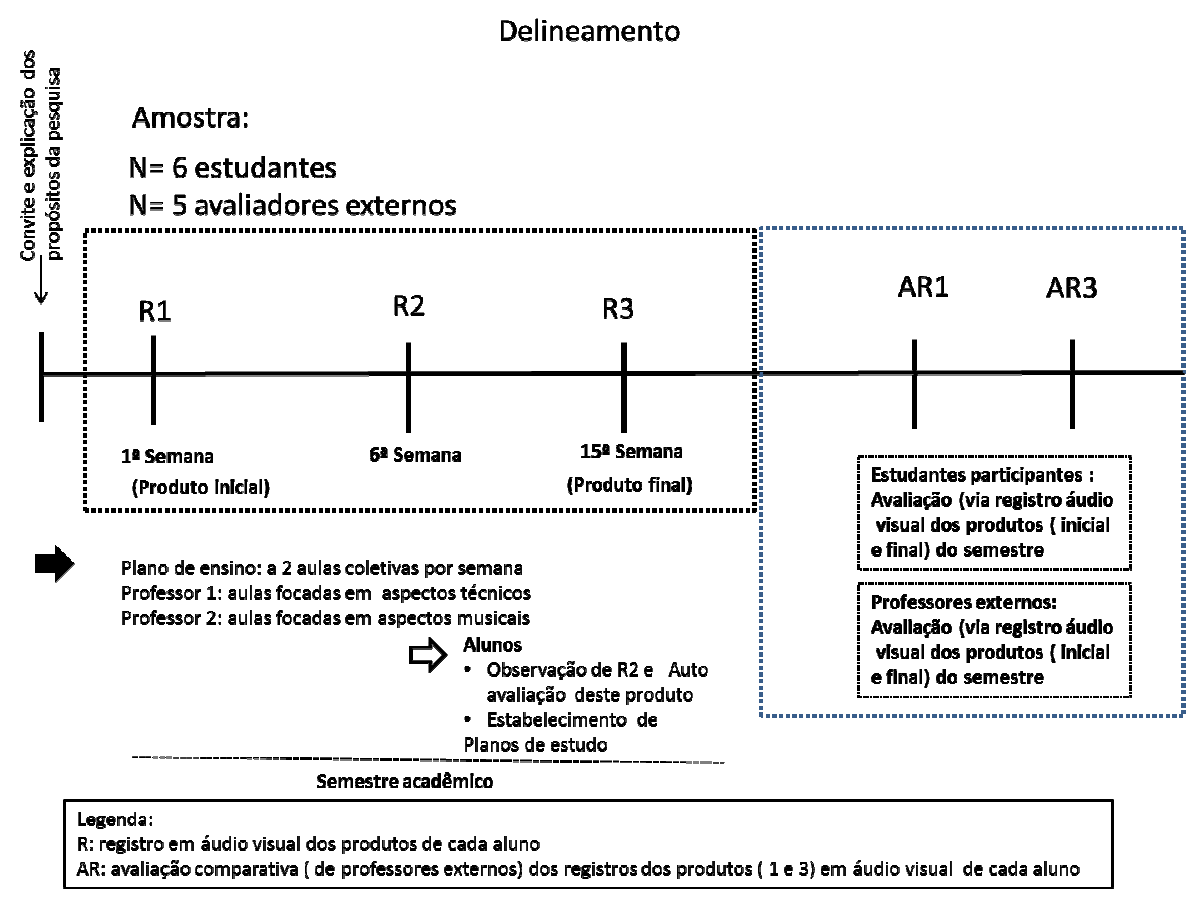

Para preservar a privacidade, os seis alunos participantes neste estudo foram identificados em todos os documentos apenas por letras (estudante $\mathrm{A}$ ao E). O mesmo procedimento foi atribuído aos avaliadores externos. Para os avaliadores externos, o primeiro e o último vídeo foram posteriormente disponibilizados via Chasquebox. O texto de apresentação das tarefas a serem realizadas pelos avaliadores contemplou as seguintes questões norteadoras: (i) destacar o aspecto que em sua opinião abalizada mostrou maior progresso; (ii) destacar o aspecto que em sua opinião abalizada mostrou menor progresso; (iii) avaliar os resultados demonstrados na gravação (R3), ao final do semestre, considerando o nível de habilidade e conhecimento do instrumento demonstrados na primeira gravação e um semestre de 
aulas; (iv) opinar, sinceramente, se este formato de aulas parece positivo como uma alternativa para atender um número maior com resultados positivos e menos horas/aula por professor.

\section{Resultados e Discussões}

A apresentação dos resultados será inicialmente realizada pelo cruzamento e pela comparação das apreciações realizadas pelos avaliadores externos, onde se solicitou que identificassem pontos que considerassem essenciais, em termos de maior e menor progresso. A análise do número total de incidências de aspectos apontados nas avaliações pelos avaliadores externos apontou cerca de $60 \%$ de aspectos referentes aos pontos fortes (progresso) nos estudantes. A Figura 3 apresenta o número de incidências de cada uma das categorias extraídas a partir da avaliação dos professores, expressos na qualidade de pontos fortes e pontos fortes exibidos pelos estudantes. De acordo com a Figura 3, em relação aos pontos fortes o maior número de incidências apontado pelos árbitros refere-se à técnica da mão direta, seguido do fraseado e da entonação. Com relação à técnica da mão direita, foram salientados aspectos tais como ponto de contato; divisão, uso e planejamento do arco; flexibilidade e amplitude do arco; paralelismo, distribuição e economia do arco. No tocante ao fraseado, foram apontados aspectos relacionados ao gerenciamento e ao direcionamento das linhas e na fluência dos eventos, bem como na finalização e início das frases. No critério entonação, foram apontados, aspectos referentes à qualidade na produção de som, sonoridade e a flexibilidade no vibrato. 
Figura 3 - Número de incidências de aspectos apontados pelos avaliadores externos na observação dos estudantes. Pontos fracos e pontos fortes.

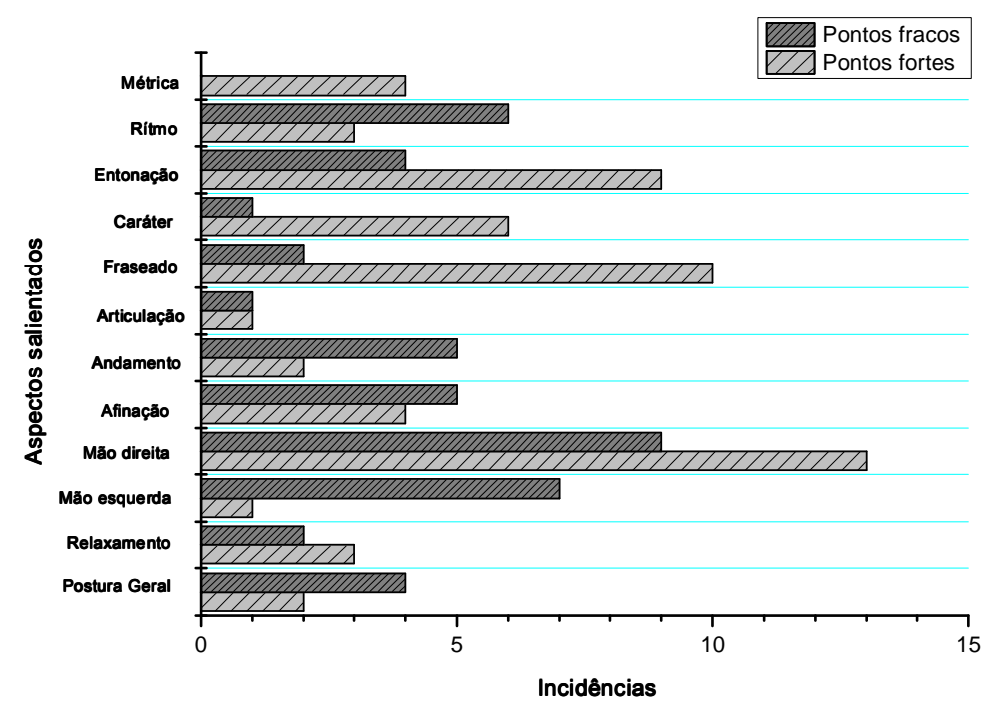

A análise das avaliações em termos de menor progresso (pontos fracos) apontaram os seguintes aspectos: mão direita, mão esquerda e ritmo, em incidências decrescentes, respectivamente. Com relação à mão direita, os árbitros apontaram problemas em termos de ponto de contato, excesso de energia do uso do arco, tensão no braço direito, cotovelo alto, pressão e velocidade do arco, por exemplo. Com relação à mão esquerda, foram comentados os seguintes parâmetros: formato da mão (mão esquerda dobrada, dedos muito próximos), posição do pulso e atividade exagerada (distante das cordas). Com relação ao ritmo, foram salientados aspectos de subdivisão (nem sempre presente, encurtando frases), ritmo errático e falta de controle. A avaliação de certos estudantes apontou, por exemplo, que embora um progresso tenha sido detectado em termos de compreensão global da métrica, aspectos pontuais de coordenação e agrupamentos rítmicos encontravam-se ainda comprometidos. Na literatura, Madison (2014) observou que embora a coordenação global da métrica forneça informações que 
possam facilitar o desempenho temporal, a manipulação das estruturas rítmicas (timing) torna-se menos precisa para intervalos mais longos, o que torna difícil de alcançar simultaneidade em sincronia com o ritmo. Em outras palavras, na presente pesquisa, segundo avaliação dos avaliadores externos, havia problema de subdivisão na compreensão e projeção de estruturas rítmicas, embora a métrica global estivesse presente na execução dos estudantes.

Do ponto de vista dos alunos, a Figura 4 apresenta a incidência, considerando os mesmos aspectos elencados pelos avaliadores externos. Para fins de comparação, foi mantida a mesma escala apresentada na Figura 3, muito embora a incidência total de aspectos apontados pelos estudantes tenha sido bem mais restrita. Nesse contexto, cerca de $70 \%$ dos aspectos apontados foram de natureza positiva (pontos fortes/percepção de progresso).

De acordo com a Figura 4, os estudantes parecem estar focados no domínio e coordenação do arco. Aspectos relacionados à métrica, ritmo e caráter não foram aí mencionados. Por outro lado, houve duas incidências com relação ao progresso em termos de exploração de dinâmica e uma menção a estilo, aspectos esses não contemplados pelos avaliadores externos.

A Figura 5 apresenta a estimativa, realizada pelos avaliadores externos, do desempenho dos estudantes no semestre, classificados nesse trabalho em três níveis: (i) abaixo da média (nota 2); (ii) na média (3) e (iii) acima da média (4).

De acordo com a Figura 5, nessa pequena população de alunos, existe uma distribuição homogênea em termos de classificação nos níveis de desempenho: há dois estudantes classificados em cada um dos três níveis. Com relação à avaliação entre os árbitros referente a um dado estudante, observa-se também uma coerência de grau atribuído para a maioria dos casos. 
Figura 4 - Número de incidências de aspectos apontados pelos árbitros na observação dos estudantes. Pontos fracos e pontos fortes.

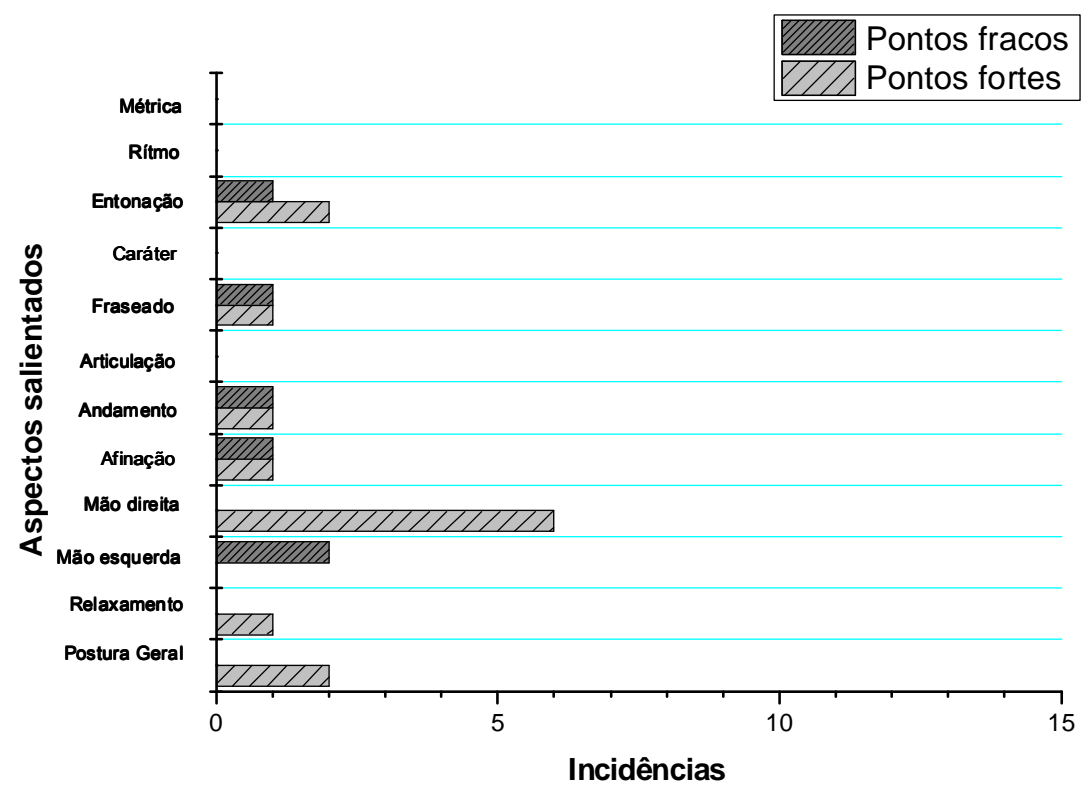

Figura 5 - Atribuição do desempenho dos estudantes no semestre, em escala de Likert (nível 2: abaixo da média; nível 3 na média; nível 4: acima da média).

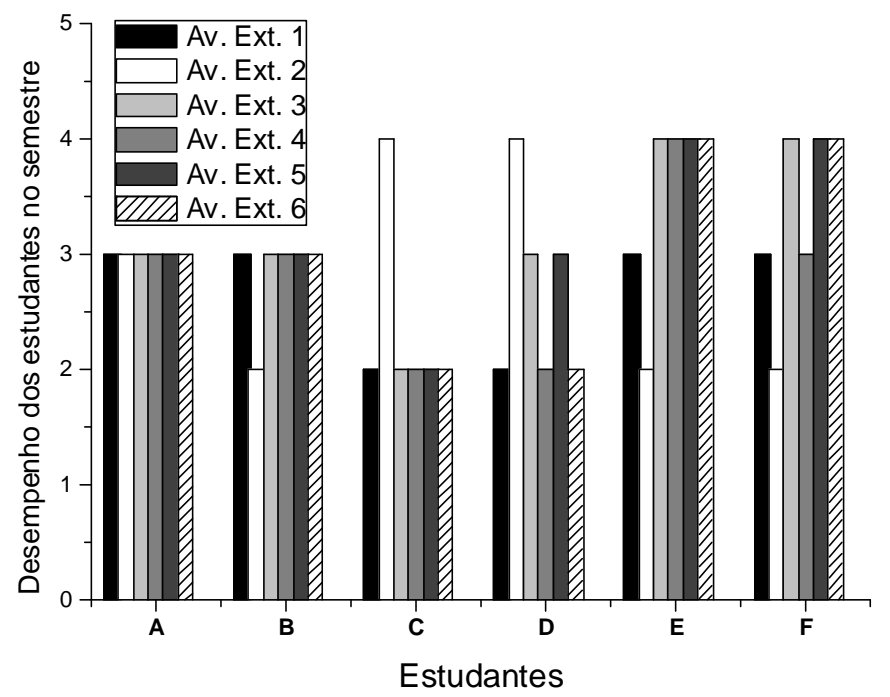


Cabe ressaltar que o Avaliador Externo 2, comparativamente aos demais árbitros, avaliou de forma distinta dos demais: os estudantes $\mathrm{C}$ e $\mathrm{D}$ (para cima) e E e $\mathrm{F}$ (para baixo). Esse árbitro, a partir de suas avaliações, pareceu valorizar os seguintes aspectos: domínio do ritmo e da afinação, fraseado, andamento, fluência e pulsação métrica. Tecnicamente, ao longo das avaliações, esse árbitro restringiu-se a comentários referentes à manipulação do arco e postura física. Assim, uma hipótese para explicar o conceito mais alto para os estudantes $C$ e D parece ser devido ao domínio de aspectos rítmicos e de afinação, respectivamente. Por outro lado, com relação à avaliação dos alunos E e $\mathrm{F}$, embora $\mathrm{O}$ árbitro $\mathrm{C}$ reconheça que tenham fluência musical, aparentemente, o grau mais baixo atribuído deveu-se à postura no instrumento e andamento, respectivamente.

A auto-avaliação dos estudantes, com base na estimulação dos três registros de seus produtos, gravados em vídeo (início, meio e fim de semestre), demonstrou um vocabulário ainda restrito e mesmo um foco limitado de observação pontual sobre problemas em seus produtos musicais. Suas percepções parecem estar refletindo aquilo que estão buscando em seus estudos individuais. Por exemplo, o estudante A, na comparação entre os vídeos R1 (início) e R3 (final) comentou:

No geral, a última gravação ficou mais rápida, mas não havia planejado isso. Também percebo as dinâmicas um pouco mais definidas (...). E o ponto de contato do arco mais para a parte inferior, sem fugir muito para a ponta como aconteceu na primeira gravação. Mas algumas partes não soam bem definidas, talvez por ter aumentado o andamento (Estudante A).

Nesta avaliação, o participante A percebe aspectos que não havia planejado, e comenta tanto sobre aspectos referentes a progressos técnicos, como sobre a expressão de dinâmicas, que parece ter sido sua meta intencional de expressão musical. Entretanto, segundo os avaliadores externos, o ponto de contato foi considerado ainda um 
aspecto deficitário no produto do final do semestre. Conforme anteriormente dito, a expressão de dinâmicas, salientada pelo estudante A, não foi observada pelos avaliadores externos. Aliás, três dos seis avaliadores apontaram como pontos fracos desse estudante: ponto de contato, fraseado e precisão rítmica.

Curiosa é a auto-avaliação do estudante $C$ que menciona:

[...] Comparando as três gravações, surpreendi-me por não ver muita diferença entre elas. Na segunda e terceira gravações, percebi que o estilo estava melhor assimilado e o domínio do arco melhorando. Na segunda gravação, o som parece mais forte e a região do arco que utilizei é diferente das outras. [...] Em geral, ainda preciso tocar mais sonoramente, pois não percebi muito progresso nesse aspecto. (Estudante C).

Com relação a esse estudante, cinco avaliadores externos consideram-no abaixo da média, acusando deficiências em sonoridade/entonação (como o próprio estudante percebeu) e afinação. No entanto, o caráter reflexivo desse estudante no tocante a sua autoavaliação aponta aqui um aspecto didático relevante para a pedagogia do instrumento dessa metodologia empregada: a auto-avaliação de vídeos de produtos registrados ao longo do semestre acadêmico pode favorecer a observação reflexiva, incentivando postura crítica em relação a sua própria atuação.

Na literatura, Daniel (2001) e Zhukov (2008) ressaltam a importância da auto-observação de vídeos por parte de estudante de instrumentos para monitorar seus próprios produtos. Por exemplo, Daniel (2001) investigou a auto-avaliação de instrumentistas universitários e desenvolveu critérios de avaliação.' O autor verificou que

1 Entre os critérios utilizados, pode-se citar: postura pessoal (entrada e saída do palco, formas de agradecimento, presença física, maneirismos, etc); aspectos musicais (escolha do repertório, precisão, coerência estilística); impressão geral (resposta pessoal e do público); reflexões sobre a performance registrada em áudio/vídeo em comparação com aquela percebida; reflexões sobre o progresso 
tal procedimento apresenta-se como ferramenta altamente valiosa para as instituições de ensino superior, pois fornece uma excelente base para as discussões entre professores e estudantes sobre as produções musicais (dos estudantes), o que pode favorecer, ao longo de sua formação acadêmica, a autonomia pessoal. O desenvolvimento da capacidade de observação e de auto-avaliação das situações de prática é considerado por Hallam (2001) como um fator de metacognição. Hallam (2001), ao investigar a prática de estudo de 21 músicos profissionais e 15 estudantes, observou que os profissionais demonstravam um fator intenso de metacognição nas situações de prática. Esses se mostravam conscientes de seus pontos fortes e fracos, além da percepção da natureza e das exigências de diferentes tarefas, bem como de potenciais resoluções de problemas.

Finalmente, com relação à forma de abordagem de ensino para esse grupo de estudantes ingressos, quatro dos seis avaliadores externos, consideram que o formato das aulas em grupo focadas nas questões técnicas e musicais, muito positivo e construtivo, conforme trechos de depoimentos abaixo:

Acredito que esse formato é muito positivo para atender mais alunos com menos horas/aula. Os resultados finais parecem normais, mostrando progresso em todo o grupo. Existe o perigo do aluno que não estuda muito, e sem o acompanhamento e limites da aula individual, consiga ir levando o semestre (Avaliador Externo 1).

Penso que essa é uma abordagem construtiva e não apenas, no caso de alunos que ingressam na graduação sem o preparo adequado. Creio que a aula de técnica em grupo, além de desafiar o aluno a desenvolver autonomia, na aplicação ao seu repertório de habilidades trabalhadas nos encontros, também estimula um espírito do grupo que o tradicional formato masterclass não é suficiente para proporcionar (Avaliador Externo 6). (planos de estudo para melhorar a prática e a performance) (DANIEL, 2001, p. 219). 
Por outro lado, dois avaliadores, mostraram-se cépticos a tal proposta principalmente ao potencial nível atingido por esses estudantes, tendo em vista que aumenta a responsabilidade da aprendizagem para o próprio aluno, estando esse ainda em um nível muito aquém daquele esperado para um ingresso em curso de graduação. O trecho abaixo ilustra o posicionamento de um desses dois avaliadores externos.

[...] Eu entendo a necessidade de se buscar alternativas para atender o número grande de alunos e admiro a iniciativa. [...].Em minha opinião, no entanto, essa organização de aulas não gerou resultados tão positivos como aulas individuais trariam. Acredito que esse resultado é mais agravado porque o nível da maioria dos alunos está abaixo do esperado no início do curso de graduação. $\mathrm{O}$ desenvolvimento será, portanto, muito mais lento e os alunos não poderão se graduar no tempo normal, também causando problemas para o curso que sofrerá pressões do governo (Avaliador Externo 3).

\section{Considerações Finais}

Nossa avaliação como professores foi positiva e continuaremos a oferecer oportunidades de aprendizado em classe para todos os alunos. Ficamos satisfeitos com a assimilação de conceitos básicos pelo grupo e com o desempenho dos alunos no material estudado. Observamos que o envolvimento dos alunos no processo de pesquisa os fez buscar mais objetividade na elaboração dos relatórios e planos de estudo. Consideramos ainda que houve um progresso significativo na capacidade de execução pública dos alunos que participaram de audições públicas, provavelmente pelo fato de estarem constantemente tocando para os colegas nas aulas coletivas.

No que tange à assimilação do conhecimento adquirido nas aulas coletivas aplicados na execução da obra de J.S Bach, constatamos que a aprendizagem, sob o ponto de vista dos avaliadores externos apresentou 
uma distribuição média, com alunos igualmente distribuídos em categorias, abaixo, acima e na média.

Embora a maioria dos alunos não tenha atingido o nível necessário para aprovação na disciplina de Violino I, constatamos que, nas suas respectivas auto-avaliações, a necessidade de repetir o semestre para obter um progresso mais consistente no futuro foi absorvida como uma etapa construtiva e positiva no desenvolvimento instrumental e musical.

\section{Referências}

BRASIL. Disponível em: $<$ http://portal.mec.gov.br/expansao $>$. Acessado em $12 / 10 / 2014$.

DANIEL, Ryan. Self-assessment in performance. British Journal of Music Education, v. 18, 2001, p. 215-226.

HALLAM, Susan. The development of metacognition in musicians: Implications for education. British Journal of Music Education, v. 18, 2001, p. 27-39.

KRAUS, Nina; CHANDRASEKARAN, Bharath. Musical training for the development of auditory skills. Nature reviews, vol. 11, 2010, p. 599-608.

MADISON. Guy. Sensorio-motor synchronization variability decreases as the number of metrical levels in the stimulus signal increases. Acta psychologica, Vol.147, 2014, p.10-16

ZHUKOV, Katie. Instrumental music teaching and learning in Australia. Berlin: Lap Lambert, 2008. 